\title{
IGF1R Positive
}

National Cancer Institute

\section{Source}

National Cancer Institute. IGF1R Positive. NCI Thesaurus. Code C128840.

Indicates that IGF1R expression has been detected in a sample. 